\title{
Effect of Lactobacillus acidophilus, Oenococcus oeni, and Lactobacillus brevis on Composition of Bog Bilberry Juice
}

\author{
Yuqi Chen ${ }^{1,+}$, Xiaoyu Ouyang ${ }^{1,+}{ }^{,}$Oskar Laaksonen ${ }^{2}{ }^{\oplus}$, Xiaoyu Liu ${ }^{1}$, Yuan Shao ${ }^{1}$, \\ Hongfei Zhao ${ }^{1}$, Bolin Zhang ${ }^{1}$ and Baoqing Zhu ${ }^{1 \text {,* }}$ \\ 1 Beijing Key Laboratory of Forestry Food Processing and Safety, Department of Food Science, College of \\ Biological Sciences and Biotechnology, Beijing Forestry University, Beijing 100083, China; \\ chenyuqi0226@163.com (Y.C.); oyxy1993@sina.com (X.O.); 15632102801@163.com (X.L.); \\ 13261361300@163.com (Y.S.); zhaohf820603@163.com (H.Z.); zhangbolin888@163.com (B.Z.) \\ 2 Food Chemistry and Food Development, Department of Biochemistry, University of Turku, \\ FI-20014 Turku, Finland; Osanla@utu.fi \\ * Correspondence: zhubaoqing@bjfu.edu.cn; Tel./Fax: +86-10-6233-8221 \\ + These authors equally contributed to this work.
}

Received: 26 August 2019; Accepted: 15 September 2019; Published: 21 September 2019

\begin{abstract}
This study investigated the impact of Lactobacillus acidophilus NCFM, Oenococcus oeni Viniflora ${ }^{\circledR}$ Oenos and Lactobacillus brevis CICC 6239 on bog bilberry juice with a considerably low $\mathrm{pH}$ and rich in anthocyanins content. Moreover, the effects of the strains on the composition of phenolic compounds, amino acids, ammonium ion, biogenic amines, reduced sugars, organic acids, and color parameters of the juice were studied. All three bacteria consumed sugars and amino acids but exhibited different growth patterns. Lactic acid was detected only in L. acidophilus inoculated juice. The content of the phenolic compounds, especially anthocyanins, decreased in juice after inoculation. The CIELa* ${ }^{*}$ analysis indicated that the juice inoculated with L. acidophilus and O. oeni showed a decrease on $\mathrm{a}^{*}$ and $\mathrm{b}^{*}$ (less red and yellow) but an increase on L (more lightness), whereas the color attributes of L. brevis inoculated juice did not significantly change. Based on this study, L. brevis showed the most optimal performance in the juice due to its better adaptability and fewer effects on the appearance of juice. This study provided a useful reference on the metabolism of lactic acid bacteria in low $\mathrm{pH}$ juice and the evolution of primary and secondary nutrients in juice after inoculated with lactic acid bacteria.
\end{abstract}

Keywords: bog bilberry juice; lactic acid bacteria; nutrients; phenolic compounds; color attributes

\section{Introduction}

The inoculation of lactic acid bacteria (LAB) represents an easy option to increase the daily consumption of fruits and it is considered as the simple and valuable biotechnology by which fruits can be processed into products for a longer shelf-life [1]. Meanwhile, the probiotic LAB can benefit human health by balancing the intestinal microorganisms, reducing the intestinal infection incidence, and enhancing the human immunity system [2]. Moreover, LAB itself can physically bind to cancerogenic compounds to reduce the toxicity of the compounds [3]. The inoculation of LAB can significantly alter and even improve the sensory quality of products made from fruits or vegetables [4]. For instance, a wide array of flavor volatiles yields after inoculation, enhancing the overall aroma of tomato juices [5]. Many factors can influence the metabolism of the LAB in a fruit matrix, and thus the appearance of the initial fruit juice after inoculation. Amino acids and carbohydrates in the juice exert the important energy sources for the replication and growth of lactic acid bacteria [6], whereas the $\mathrm{pH}$ of a juice plays an important role in determining the metabolism of bacteria [7]. 
The evolution of phenolic compounds in juice may also take place after the inoculation, resulting in an alteration of color attributes in juice products [8]. Phenolic compounds, especially anthocyanins, are typically desired components in fruit juices due their potential contribution to human health [9]. Anthocyanins are the most important phenolic compounds that take charge of the appearance of juice [10]. LAB have been reported to enhance the concentration of the total anthocyanins, phenolic compounds and flavonoids in fruit juice [11]. Co-pigmentation can take place between the monomeric anthocyanins and other compounds in the juice, which might result in the stabilization of anthocyanins and thus delay the unwanted color change in juice [12]. The contents of sugars in juices have also been reported to affect the structure of anthocyanins, leading to an alteration on the juice appearance $[13,14]$. Phenolic compounds can also be metabolized by LAB to produce some aroma-active volatile compounds, which could potentially improve the sensory quality of the original juice [15].

Amino acids are the primary nitrogen source for the growth of lactic acid bacteria in juice after inoculation [16]. Amino acids can be metabolized into biogenic amines with the activity of lactic acid bacteria [17]. For example, tyramine, spermidine, cadaverine, putrescine, and phenethylamine are yielded from the metabolism of tyrosine, arginine, lysine, ornithine, and phenylalanine, respectively [17].

Bog bilberry (Vaccinium uliginosum L.) belongs to a low-bush blueberry shrub that is natively grown in the cool temperature areas [18]. It is one of the most abundant wild blueberries in the Greater Khingan Range, Northeast China, most of Europe from the Arctic to the mountains of Southern Europe, Georgia, temperate Asia and North America $[19,20]$. Bog bilberry juice contains high levels of bioactive nutrients, such as anthocyanins, with multiple health beneficial properties [21]. The consumption of bog bilberry juice can reduce cardiovascular diseases, prevent cancer occurrences, and inhibit diabetes and obesity $[22,23]$. However, bog bilberry juice possesses low $\mathrm{pH}(\mathrm{pH}<3.0)$ compared to some other common fruit juices, making the juice too sour to be freshly consumed.

Processing fruit and berry juices by using LAB inoculation has gained popularity in recent years aiming for novel non-alcoholic fermented beverages [1,11,24-27]. It is a potential method to adjust the acidity of the juice, although lactic acid bacteria might have difficulties to survive in juices with $\mathrm{pH}<3.0$. The adjustment of $\mathrm{pH}$ in juice could enhance the growth for LAB strains. However, the alteration of $\mathrm{pH}$ could alter the original flavor of the berry, which might affect the acceptability of the juice to consumers. Anthocyanins are the primary pigments in juice, and they are not equally stable in a higher $\mathrm{pH}$ condition. The adjustment of $\mathrm{pH}$ could alter the composition of anthocyanins, leading to a change on the appearance of bog bilberry juice. Recent studies showed that L. plantarums strains could consume malic acid to produce lactic acid in juices with $\mathrm{pH}<3.0$ made from bog bilberry and sea buckthorn $(\mathrm{pH}<3.0)[25,28]$. To the best of the authors' knowledge, there are no published studies to investigate the growth and metabolism of LAB in bog bilberry juice or to evaluate the effect of LAB on the alteration of chemical constituents in bog bilberry juice.

The present study aimed to understand the effects of different LAB, i.e., their growth and metabolism, on the chemical composition of bog bilberry juice after inoculation. L. acidophilus is a probiotic strain available in conventional foods (milk, yogurt, and toddler formula) and dietary supplements [29]. L. brevis is a heterofermentative gram-positive organism always used in probiotic products [30]. For example, L. brevis was inoculated into black raspberry juice to enrich $\gamma$-aminobutyric acid [31] O. oeni has excellent tolerance to harsh conditions and it is generally applied as starters in the malolactic fermentation period of red wine vinification to convert malic acid to lactic acid [32]. In this study, L. brevis CICC 6239 (Lactobacillus genus), L. acidophilus NCFM (Lactobacillus genus), or O. oeni Viniflora ${ }^{\circledR}$ Oenos (Oenococcus genus) was inoculated into bog bilberry juice. The evolution of the primary and secondary nutrients in these juices, including sugars, organic acids, amino acids, biogenic amines, and phenolic compounds together with the changes of color attributes, were investigated and compared. The findings from this study might provide useful information on the metabolism of lactic acid bacteria in juice with naturally low $\mathrm{pH}$, and further could introduce a potential method to improve the sensory and nutritional quality of bog bilberry juice using lactic acid bacteria. 


\section{Materials and Methods}

\subsection{Bog Bilberry Juice}

Fully ripe bog bilberries were hand-harvested in 2014 from Great Khingan Mountains. The berries were immediately frozen at $-20{ }^{\circ} \mathrm{C}$ in plastic bags and then transported to the laboratory. During the juice preparation, the bog bilberry was thawed, crushed, and then squeezed into juice with a pneumatic presser (KSC125 × 400, Tungming Pneumatic Co., Ltd., Dongguan, China). Subsequently, the raw juice was clarified under $+4{ }^{\circ} \mathrm{C}$ until the turbidity dropped to below 40 NTU and then filtered through $0.45 \mu \mathrm{m}$ crossflow filtration membranes to eliminate the solids and microorganisms.

\subsection{Lactic Acid Bacterial Strains}

Three lactic acid bacterial strains were selected in this study. L. brevis CICC 6239, a strain originally isolated from Chinese pickle, was provided by China Center of Industrial Culture Collection (Beijing, China). L. acidophilus (NCFM) and O. oeni (Viniflora ${ }^{\circledR}$ Oenos) were commercial strains purchased from Danisco (Horsholm, Denmark).

\subsection{Inoculation of the Strains}

The revitalization of these strains followed a published method [33]. Briefly, each strain was inoculated in $5 \mathrm{~mL}$ of the Man, Rogosa and Sharpe (MRS) medium [34] for $48 \mathrm{~h}$ at $37^{\circ} \mathrm{C}$, followed by another 48-h incubation under the same condition after passaging the strain to the same volume of the medium. When the microbial density reached $10^{8} \mathrm{CFU} / \mathrm{mL}, 10 \mathrm{~mL}$ of the fluid medium was centrifuged at $5000 \mathrm{rpm}$ for $10 \mathrm{~min}$, and then washed using $10 \mathrm{~mL}$ normal saline solution twice to harvest the strain. The harvested bacteria were inoculated into $100 \mathrm{~mL}$ bog bilberry juice. The inoculation of each strain into juice was carried out in triplicate. Afterwards, the juices were transferred into an incubator and placed at $+23^{\circ} \mathrm{C}$. The sampling took place at the $0,1,2,3,7$ and 14 days, respectively. After sampling, the viable cultures in the juices were counted using the standard plate count method [35] and then the juices were immediately centrifuged at $5000 \mathrm{rpm}$ for $10 \mathrm{~min}$ to remove the bacteria from the juice. The centrifuged juices were then filtered through $0.45 \mu \mathrm{m}$ filters and frozen at $-20{ }^{\circ} \mathrm{C}$ for further analysis.

\subsection{Reducing Sugars}

A Shimadzu LC-20AT high performance liquid chromatograph (Shimadzu, Japan), equipped with a RID-20A detector (Shimadzu, Japan), was used to analyze the sugar consumption in the juice after inoculating lactic acid bacteria. A Venusil Innova Durashell NH2 column $(4.6 \times 250 \mathrm{~mm}$, $5 \mu \mathrm{m}$, Bonna-Agela Technologies Co. Ltd., Tianjin, China) was used to separate glucose and fructose. The analysis program followed the instruction of the chromatographic column manufacture. The mobile phase was comprised of (A) acetonitrile and (B) water. The column temperature was maintained at $+25^{\circ} \mathrm{C}$ and the elution was set at an isocratic flow rate of $0.8 \mathrm{~mL} / \mathrm{min}(\mathrm{A})$ and $0.2 \mathrm{~mL} / \mathrm{min}(\mathrm{B})$ for $13 \mathrm{~min}$ with an injection volume of $20 \mu \mathrm{L}$ of the filtered juices. The external standard glucose and fructose were used to identify and quantify the compounds in the juices.

\section{5. $\mathrm{pH}$ and Organic Acids}

A PHS-3C pH meter (INESA Instrument Ltd., Shanghai, China) was used to measure the $\mathrm{pH}$ value of the juice. The organic acids in the juice were determined using a published HPLC method [36]. A Venusil XSB C18 column $(4.6 \times 250$ mm, $5 \mu \mathrm{m}$, Bonna-Agela Technologies Co. Ltd., Tianjin, China) was used to separate the compounds on a Shimadzu LC-20AT LC system (Shimadzu, Japan). The mobile phase consisted of formic acid: methyl alcohol: water (0.1:3.0:96.9, v/v/v) and a 20-min isocratic elution program was used with a flow rate of $0.5 \mathrm{~mL} / \mathrm{min}$. The injection volume was $20 \mu \mathrm{L}$. The external organic acid standards were used to quantify the organic acids in the juice. 


\subsection{Amino Acids, Ammonium Ion and Biogenic Amines}

The analysis of amino acids, ammonium ion and biogenic amines in the juice after inoculation followed a published method with minor modifications [37]. Briefly, $500 \mu \mathrm{L}$ juice was mixed with $10 \mu \mathrm{L}$ $1.00 \mathrm{~g} / \mathrm{L}$ 2-aminoadipic acid (internal standard), $375 \mu \mathrm{L}$ methanol, $15 \mu \mathrm{L}$ diethyl ethoxy methylene malonate, and $875 \mu \mathrm{L} 1 \mathrm{~mol} / \mathrm{L}$ borate buffer ( $\mathrm{pH}$ 9.0). The mixture was sonicated for $30 \mathrm{~min}$ and then heated at $+70{ }^{\circ} \mathrm{C}$ for $2 \mathrm{~h}$. Afterwards, the resultant mixture was cooled down to room temperature and then filtered through $0.22 \mu \mathrm{m}$ nylon filters. The same HPLC apparatus as in the analysis of the organic acids was used. The mobile phase consisted of (A) acetonitrile: methanol $(4: 1, v / v)$ and (B) $25 \mathrm{mM}$ acetate buffer ( $0.02 \%$ sodium azide, $\mathrm{pH} 5.8)$. The injection volume was $20 \mu \mathrm{L}$ and the flow rate was $0.9 \mathrm{~mL} / \mathrm{min}$. The gradient was programmed as follows: $0-20 \mathrm{~min}, 90 \% \mathrm{~B}$ isocratic; $20-30.5 \mathrm{~min}$, $90 \% \mathrm{~B}$ to $83 \% \mathrm{~B}$; $30.5-33.5 \mathrm{~min}, 83 \% \mathrm{~B}$ isocratic; $33.5-65 \mathrm{~min}, 83 \% \mathrm{~B}$ to $73 \% \mathrm{~B}$; $65-73 \mathrm{~min}, 73 \% \mathrm{~B}$ to $28 \% \mathrm{~B}$; $73-78 \mathrm{~min}, 28 \% \mathrm{~B}$ to $18 \% \mathrm{~B}$; $78-82 \mathrm{~min}, 18 \% \mathrm{~B}$ to $0 \% \mathrm{~B} ; 82-85 \mathrm{~min}, 0 \% \mathrm{~B}$ isocratic; $85-90 \mathrm{~min}, 0 \% \mathrm{~B}$ to $90 \% \mathrm{~B}$; and $90-93 \mathrm{~min}, 90 \% \mathrm{~B}$ isocratic. The external standard amino acids, ammonium ion, and biogenic amines were also derivatized using the same procedure, and the quantitation of these compounds was performed by the regression curve generated through the peak ratio of external standard over the internal standard versus the concentration of the external standard.

\subsection{Anthocyanin Compounds}

An Agilent 1100 HPLC system coupled with an MSD Trap VL ion-trap mass spectrometer (Agilent Technologies, Santa Clara, CA, USA) was used for the analysis of anthocyanins $[19,38]$. A Kromasil-C18 column $(250 \times 4.6 \mathrm{~mm}, 5 \mu \mathrm{m})$ was used for the separation of anthocyanins. The mobile phase consisted of (A) $6 \%(v / v)$ acetonitrile containing $2 \%(v / v)$ formic acid, and (B) $54 \%(v / v)$ acetonitrile containing $2 \%$ $(v / v)$ formic acid. The column was set at $50{ }^{\circ} \mathrm{C}$ and the flow rate was $1.0 \mathrm{~mL} / \mathrm{min}$. A sample volume of $30 \mu \mathrm{L}$ was injected to the system. The gradient was as follows: $0-1 \mathrm{~min}, 10 \% \mathrm{~B} ; 1-18 \mathrm{~min}, 10 \% \mathrm{~B}$ to $25 \% \mathrm{~B}$; $18-20 \mathrm{~min}, 25 \% \mathrm{~B}$ isocratic; $20-30 \mathrm{~min}, 25 \% \mathrm{~B}$ to $40 \% \mathrm{~B} ; 30-35 \mathrm{~min}, 40 \% \mathrm{~B}$ to $75 \% \mathrm{~B}$; and $35-40 \mathrm{~min}$, $70 \% \mathrm{~B}$ to $100 \% \mathrm{~B}$. The wavelength for the detection was set at $525 \mathrm{~nm}$. Positive electrospray ionization was used with the nebulizer pressure of $35 \mathrm{psi}$, the temperature of $+325^{\circ} \mathrm{C}$, and the dry gas flow rate of $10 \mathrm{~mL} / \mathrm{min}$. A full scan mode from $\mathrm{m} / \mathrm{z} 100$ to 1500 was recorded. Anthocyanins were tentatively identified by comparing their mass spectrum with the references $[39,40]$. The external standard malvidin-3-O-glucoside was used for the quantitation of anthocyanins.

\subsection{Non-Anthocyanin Phenolic Compounds}

An Agilent 1200 HPLC system coupled with an MSD Trap VL ion-trap mass spectrometer (Agilent Technologies, Santa Clara, CA, USA) was used for the analysis of phenolic compounds [19]. An Agilent Zorbax SB-C18 reverse column $(3 \times 50 \mathrm{~mm}, 1.8 \mu \mathrm{L})$ was used for the separation of phenolic compounds. The mobile phase consisted of (A) $1 \%$ acetic acid in acetonitrile and (B) $1 \%$ acetic acid in water. The column was set at $+25^{\circ} \mathrm{C}$ with a $1.0 \mathrm{~mL} / \mathrm{min}$ flow rate. The gradient was as follows: $0-5 \mathrm{~min}, 0 \% \mathrm{~B}$ to $5 \% \mathrm{~B} ; 5-10 \mathrm{~min}, 5 \% \mathrm{~B}$ to $8 \% \mathrm{~B} ; 10-15 \mathrm{~min}, 8 \% \mathrm{~B}$ to $12 \% \mathrm{~B} ; 15-20 \mathrm{~min}$, $12 \% \mathrm{~B}$ to $18 \% \mathrm{~B} ; 20-22 \mathrm{~min}, 18 \% \mathrm{~B}$ to $22 \% \mathrm{~B} ; 22-24 \mathrm{~min}, 22 \% \mathrm{~B}$ to $35 \% \mathrm{~B}$; and $24-28 \mathrm{~min}, 35 \% \mathrm{~B}$ to $100 \% \mathrm{~B}$. The wavelength on the diode array detector was set at $280 \mathrm{~nm}$. The negative mode was used in the electrospray ionization, and the nebulizer pressure was set at $35 \mathrm{psi}$. The temperature and flow rate of dry gas were $+325{ }^{\circ} \mathrm{C}$ and $10 \mathrm{~mL} / \mathrm{min}$, respectively. Mass spectrum was recorded using a full scan mode from $\mathrm{m} / \mathrm{z} 100$ to 1500 . Phenolic compounds were tentatively identified by comparing their mass spectrum with the references [40]. Catechin, quercetin, gallic acid, caffeic acid, and chlorogenic acid were used for the quantitation of flavanols, flavonols, hydroxybenzoic acids, hydroxycinnamic acids, and chlorogenic acid, respectively.

\subsection{Color Attributes}

The CIELa* $b^{*}$ assay was used to estimate the color attributes of the juice [41]. The juice was filtered through $0.22 \mu \mathrm{m}$ filters and the transmittance was recorded at 440, 530, and $600 \mathrm{~nm}$ on a Unico 
4802 UV/Vis spectrophotometer (Unico Instrument Co. Ltd., Shanghai, China). Distilled water was used for the reference and the value of $\mathrm{L}^{*}, \mathrm{a}^{*}, \mathrm{~b}^{*}$, and $\Delta \mathrm{E}^{*}$ were used to express the color lightness, redness, greenness, and color difference, respectively.

\subsection{Statistical Analysis}

The data were expressed as the mean \pm standard deviation of triplicate tests. One-way analysis of variance (ANOVA), under Duncan's multiple rank test, was used to compare the means at a significant level of 0.05 using SPSS 23.0 Statistical Software (IBM, Armonk, North Castle, NY, USA). The heatmap, clustering analysis, two-way ANOVA and principal component analysis were carried out on MetaboAnalyst (http://www.metaboanalyst.ca, McGill University, Montreal, QC, Canada). Auto-scaling (mean-centered and divided by the standard deviation of each variable) was used to normalize the data.

\section{Results}

\subsection{Bacterial Growth in Bog Bilberry Juice}

L. brevis decreased rapidly during the first two days (the growth ratio from 1.00 to 0.65; calculated using the CFU at each sampling day over its initial CFU after inoculation), then increased (from 0.65 to 0.80 ), and then kept slowly increasing until day 14 (from 0.8 to 0.9 ) (Figure 1 and Table S1). Similarly, the growth ratio of O. oeni also showed a decrease at the beginning (from 1.00 to 0.75 ), and then increased from 0.75 to 0.86 until day 3. Although different from L. brevis, the growth ratio of O. oeni peaked at day 7 (from 0.86 to 1.03 ), and then kept a slowly decreasing until day 14 (to 1.02). In addition, $O$. oeni showed a higher growth in the juice than L. brevis during all the process. Although different from L. brevis and O. oeni, L. acidophilus gradually decreased after inoculation. The growth ratio of $L$. acidophilus was higher than the other two bacteria at first three days but decreased to the lowest at day $7(0.82)$.

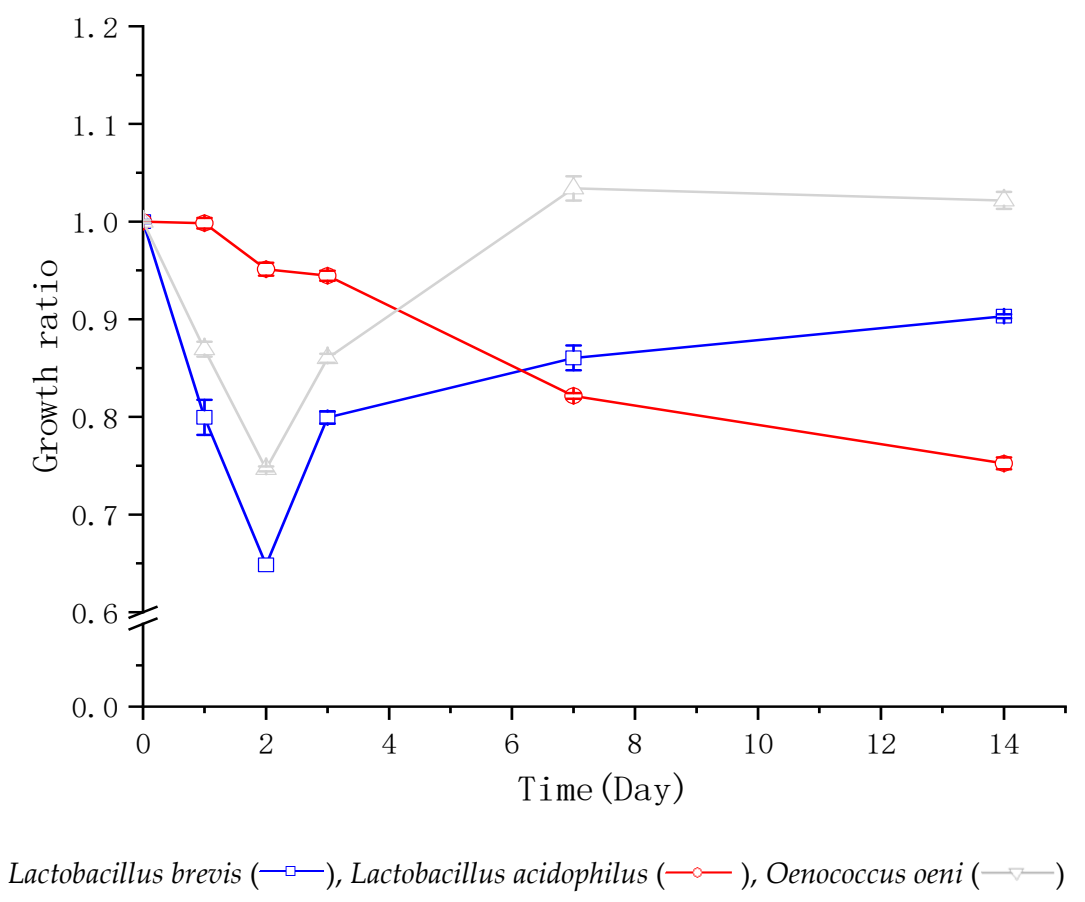

Figure 1. Bacterial growth in bog bilberry juice in 14 days. "——"“- — " and " - $\square$ " represent the growth pattern of Lactobacillus brevis, Lactobacillus acidophilus, and Oenococcus oeni, respectively. The growth is calculated using the CFU at each sampling day over its initial CFU before inoculation. The data are the mean \pm standard deviation of triplicate tests. 


\subsection{Changes in Chemical Components and $\mathrm{pH}$ in Juice after Inoculation}

\subsubsection{Reducing Sugars}

The inoculation of lactic acid bacteria caused significant decreases on the content of reducing sugars, as expected (Table S2 and Figure 2). O. oeni showed faster consuming speed of reducing sugars than the other two strains. The evolution of glucose and fructose in these LAB inoculated bog bilberry juices showed similar kinetics (Table S2 and Figure 2). However, glucose was preferable for these strains than fructose. For example, the reducing rate of the glucose content exceeded $50 \%$ in all the samples after the incubation, whereas the largest consumption rate of the fructose content was $35.1 \%$ in the juice inoculated with L. acidophilus. The levels of these two monosaccharides also declined the fastest in the juice inoculated with O. oeni.

\subsubsection{Organic Acids and $\mathrm{pH}$}

Quinic acid, malic acid, and citric acid appeared to be the dominant organic acids in the bog bilberry juice (Table S2 and Figure 2). The lactic acid bacteria inoculation did not significantly alter the composition of these organic acids, except for lactic acid which yielded in the L. acidophilus inoculated juice. The content of citric acid and malic acid experienced some fluctuations in the juice treated by O. oeni and L. acidophilus, respectively. Similarly, quinic acid in the juice inoculated with L. brevis exhibited a concentration fluctuation. The rest of the organic acids showed the similar content in the juice before and after the treatment. In addition, the inoculation of these lactic acid bacteria had limited impact on the $\mathrm{pH}$ (Table S2 and Figure 3).

\subsubsection{Amino Acids, Ammonium Ion and Biogenic Amines}

Significant alterations of the total amino acid contents were observed in the juices, and the evolution patterns during fermentation varied notably in the juices inoculated with the three LAB strains (Table S3 and Figure 2). For example, at the first two days of the process, the total amino acid content remained similar in the treated juices, whereas a decrease in the total content was observed in the L. brevis and the O. oeni processed juices after 3 days of the inoculation. L. brevis and O. oeni exhibited much higher consumptions of the amino acids compared to L. acidophilus. The trends remained similar until the end of the fermentations.

In the first three days of the incubation period, the most abundant amino acid in the bog bilberry juice, valine, exhibited an increase in content in all juices inoculated with the LAB strains (Table S3). On the contrary, the juice inoculated with L. acidophilus resulted in an increase in the concentration of the amino acid. At the same time, the content of glutamine, $\gamma$-aminobutyric acid, isoleucine, proline, and aspartic acid increased. The O. oen $i$ inoculation led to a concentration increase on valine and tryptophan in the juice. Ornithine showed a dramatic content elevation in the first 2 days (7-time in L. brevis and 10-time in O. oeni), whereas the content increase of ammonium ion was approximately 1.5-2 times. However, a significant content decrease on valine, asparaginate and glutamine happened after 3 days of the incubation, and these primary components reduced to a low level after 7 days. More importantly, these strains showed the difference on the consumption of amino acids in the juice. For instance, L. brevis and $O$. oeni showed a higher consumption rate on asparagine, glutamine, arginine, and aspartic acid compared to L. acidophilus. Meanwhile, the content of tyrosine experienced some fluctuations in the L. acidophilus and O. oeni inoculated juices, whereas L. brevis strain did not significantly metabolize tyrosine in the juice. In addition, it should be noted that the amount of tryptophan and phenylalanine declined to a low level in the juice inoculated with these lactic acid bacteria, except for phenylalanine in the L. acidophilus treated juice. Surprisingly, isoleucine accumulated in the juice with L. brevis after the incubation and its content was approximately 8 times higher than its content before the inoculation. Histidine, aspartic acid, threonine, $\beta$-alanine, proline, $\gamma$-aminobutyric acid, glycine and serine were significantly metabolized by the strains at the end of incubation.

Biogenic amines are produced from amino acids and these compounds have been confirmed to possess multiple bioactive functions [42]. The biogenic amines remained at a low content in the juice 
throughout the incubation process, whereas their corresponding amino acids were almost consumed after 3 days of the inoculation (Table S3). Histamine was the dominant biogenic amine in the initial juice, and its evolution was different in the samples inoculated with the LAB strains. For example, the level of histamine increased in the juice with L. brevis and L. acidophilus, whereas the inoculation of O. oeni caused a decrease in its content.

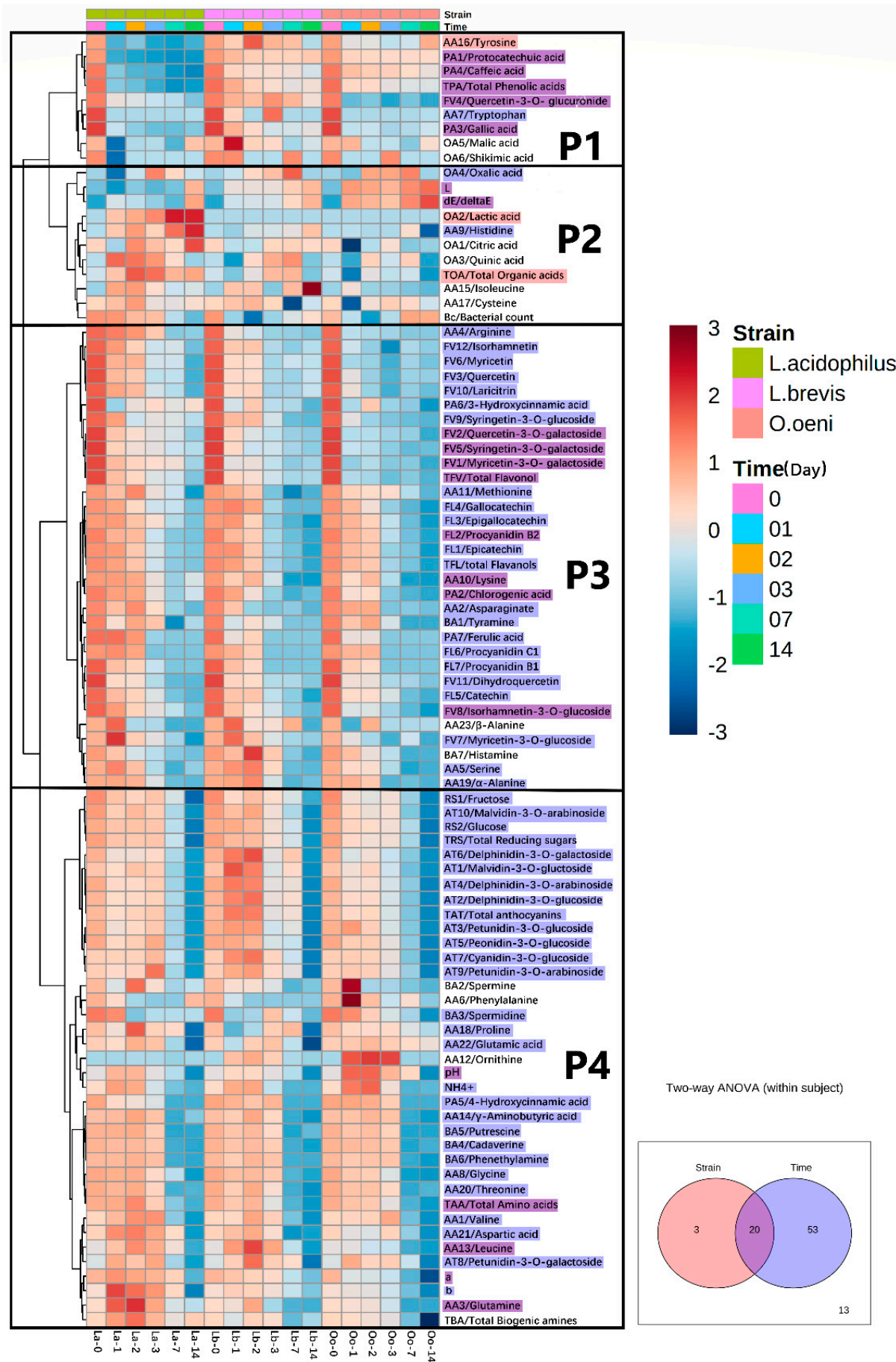

Figure 2. Evolution of all the compounds in the inoculated bog bilberry juices 0-14 days and a two-way ANOVA analysis for both strain and time effects and their interactions. The compound names colored with " $"$ " and " " " shows the variables mainly affected by strain or time, respectively; the compounds colored with " $\square$ " show the variables affected by both strain difference and time $(p<0.05)$. Compounds without color are not affected by the main effects. 
A

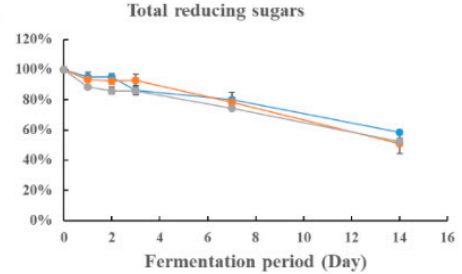

D

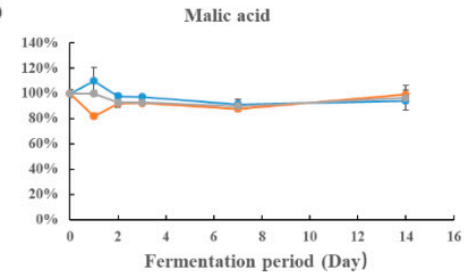

G

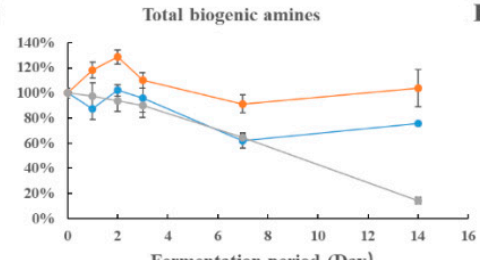

$\mathbf{J}$

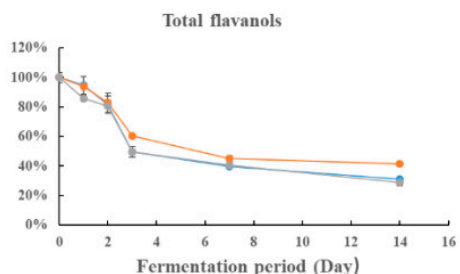

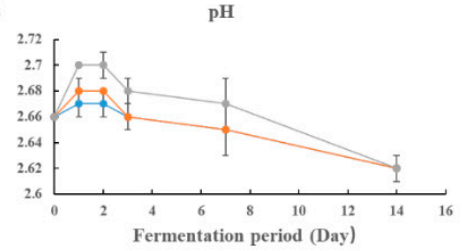

E

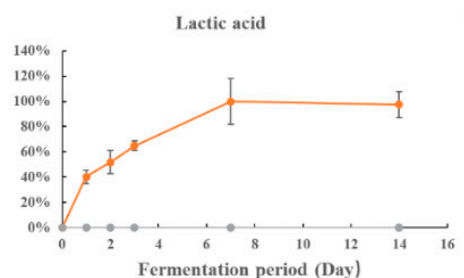

H

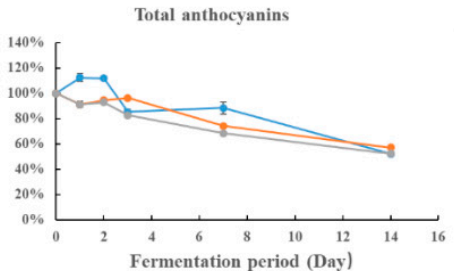

C

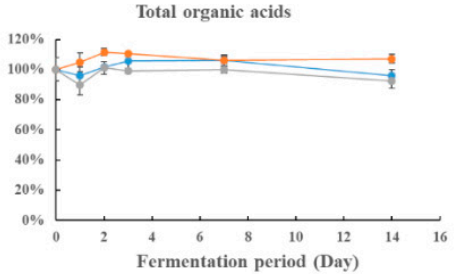

$\mathbf{F}$
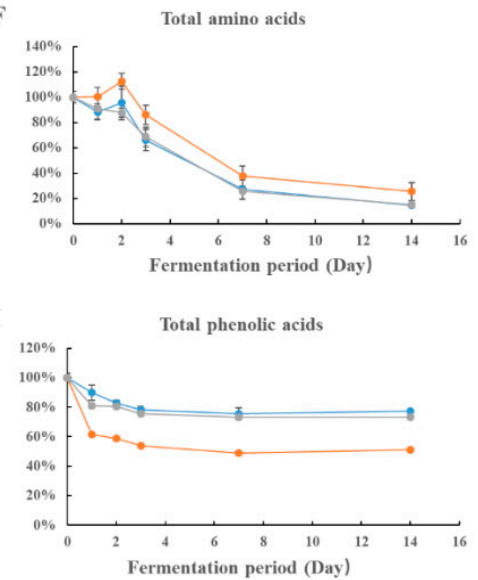

$\mathbf{K}$

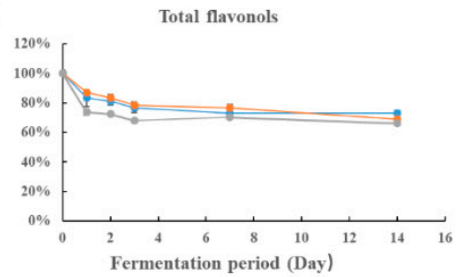

Figure 3. Primary and secondary nutrients in bog bilberry juice in 14 days. "-,", "-, " and "-, " represent the growth pattern of Lactobacillus brevis, Lactobacillus acidophilus, and Oenococcus oeni, respectively. The data are the mean \pm standard deviation of triplicate tests.

\subsubsection{Anthocyanins}

Malvidin-3-O-gluctoside, delphinidin-3-O-glucoside, and petunidin-3-O-glucoside were the dominated anthocyanins in the original bog bilberry juice and their contents accounted for approximately $77 \%$ of the total anthocyanin content (Table 1 ). The content of all anthocyanins decreased after the inoculation, and the most significant decreases occurred after 7 days from the inoculation. (Figure 2). After the whole incubation period, the anthocyanins decreased their content by approximately $40 \%$. The LAB strains had different impacts on the alteration of the concentration of the anthocyanins in the juice. For instance, the inoculation of L. brevis resulted in an increase on the anthocyanin contents at the beginning of the incubation, followed by a decrease by 7 days of the incubation. However, its concentration decrease was the least compared to the other strains inoculated juices. After the whole incubation period, the juice with L. acidophilus exhibited the lowest loss of the content of total anthocyanins. The juice inoculated with L. acidophilus contained higher concentration of petunidin-3-O-glucoside, delphinidin-3-O-arabinoside, peonidin-3-O-glucoside, cyanidin-3-O-glucoside, and petunidin-3-O-arabinoside. Surprisingly, L. brevis enhanced the accumulation of malvidin-3-O-gluctoside, delphinidin-3-O-glucoside, delphinidin-3-O-galactoside, and cyanidin-3-O-glucoside in the juice at the early stage of the incubation. Additionally, petunidin-3-O-galactoside increased its concentration in these strains inoculated juices during the incubation process. 
Table 1. Content of anthocyanins in bog bilberry juice inoculated with three lactic acid bacteria strains in 14 days.

\begin{tabular}{|c|c|c|c|c|c|c|c|}
\hline \multirow{2}{*}{ Compound (mg/L) } & \multirow{2}{*}{ Strain } & \multicolumn{6}{|c|}{ Time (Day) } \\
\hline & & 0 & 1 & 2 & 3 & 7 & 14 \\
\hline \multirow[t]{3}{*}{ Malvidin-3-O-gluctoside } & L. brevis & $108.23 \pm 0.18 \mathrm{Ac}$ & $131.09 \pm 2.45 \mathrm{Bd}$ & $123.60 \pm 0.56 \mathrm{Bd}$ & $94.68 \pm 2.60 \mathrm{Ab}$ & $102.51 \pm 5.59 \mathrm{Bbc}$ & $63.83 \pm 1.66 \mathrm{Aa}$ \\
\hline & L. acidophilus & $108.23 \pm 0.18$ Acd & $101.67 \pm 0.12 \mathrm{Ac}$ & $109.22 \pm 2.95 \mathrm{Ad}$ & $106.43 \pm 1.74 \mathrm{Bcd}$ & $83.24 \pm 0.13 \mathrm{Ab}$ & $67.68 \pm 1.62 \mathrm{Aa}$ \\
\hline & O. oeni & $108.23 \pm 0.18 \mathrm{Ae}$ & $99.37 \pm 2.16 \mathrm{Ad}$ & $104.37 \pm 1.26$ Ade & $92.24 \pm 0.48 \mathrm{Ac}$ & $77.34 \pm 1.73 \mathrm{Ab}$ & $64.00 \pm 0.65 \mathrm{Aa}$ \\
\hline \multirow[t]{3}{*}{ Delphinidin-3-O-glucoside } & L. brevis & $82.04 \pm 0.52 \mathrm{Abc}$ & $90.59 \pm 4.51 \mathrm{Bc}$ & $93.82 \pm 1.17 \mathrm{Bc}$ & $69.29 \pm 2.57 \mathrm{ABb}$ & $72.10 \pm 4.46 \mathrm{Bb}$ & $38.88 \pm 1.10 \mathrm{ABa}$ \\
\hline & L. acidophilus & $82.04 \pm 0.52 \mathrm{Ad}$ & $73.10 \pm 1.28 \mathrm{Ac}$ & $74.31 \pm 0.20 \mathrm{Ac}$ & $76.02 \pm 0.59 \mathrm{Bc}$ & $59.07 \pm 0.14 \mathrm{Ab}$ & $42.65 \pm 1.03 \mathrm{Ba}$ \\
\hline & O. oeni & $82.04 \pm 0.52 \mathrm{Ae}$ & $73.46 \pm 2.17 \mathrm{Ad}$ & $73.31 \pm 0.14 \mathrm{Ad}$ & $65.34 \pm 1.09 \mathrm{Ac}$ & $52.90 \pm 1.02 \mathrm{Ab}$ & $38.34 \pm 0.38 \mathrm{Aa}$ \\
\hline \multirow{3}{*}{ Petunidin-3-O-glucoside } & L. brevis & $65.75 \pm 0.55 \mathrm{Ac}$ & $68.51 \pm 0.80 \mathrm{Bc}$ & $68.34 \pm 1.24 \mathrm{Bc}$ & $53.54 \pm 1.05 \mathrm{Ab}$ & $55.31 \pm 2.23 \mathrm{Bb}$ & $35.21 \pm 0.04 \mathrm{Aa}$ \\
\hline & L. acidophilus & $65.75 \pm 0.55 \mathrm{Ae}$ & $57.59 \pm 1.02 \mathrm{Ac}$ & $59.74 \pm 0.21 \mathrm{Ac}$ & $62.36 \pm 0.02 \mathrm{Bd}$ & $49.01 \pm 0.37 \mathrm{Ab}$ & $39.14 \pm 0.55 \mathrm{Ca}$ \\
\hline & O. oeni & $65.75 \pm 0.55 \mathrm{Ae}$ & $68.51 \pm 0.80 \mathrm{Be}$ & $61.36 \pm 0.99 \mathrm{Ad}$ & $54.33 \pm 0.22 \mathrm{Ac}$ & $46.13 \pm 1.07 \mathrm{Ab}$ & $36.98 \pm 0.08 \mathrm{Ba}$ \\
\hline \multirow{3}{*}{ Delphinidin-3-O-arabinoside } & L. brevis & $19.46 \pm 0.30 \mathrm{Ac}$ & $21.42 \pm 0.80 \mathrm{Bc}$ & $21.07 \pm 0.16 \mathrm{Bc}$ & $15.84 \pm 0.27 \mathrm{Ab}$ & $16.09 \pm 0.84 \mathrm{Bb}$ & $8.86 \pm 0.26 \mathrm{Ba}$ \\
\hline & L. acidophilus & $19.46 \pm 0.30 \mathrm{Ad}$ & $17.05 \pm 0.61 \mathrm{Ac}$ & $17.01 \pm 0.10 \mathrm{Ac}$ & $17.86 \pm 0.25 \mathrm{Bc}$ & $13.26 \pm 0.25 \mathrm{Ab}$ & $9.86 \pm 0.22 \mathrm{Aa}$ \\
\hline & O. oeni & $19.46 \pm 0.30 \mathrm{Ad}$ & $16.41 \pm 0.81 \mathrm{Ac}$ & $16.58 \pm 0.24 \mathrm{Ac}$ & $15.11 \pm 0.01 \mathrm{Ac}$ & $12.58 \pm 0.17 \mathrm{Ab}$ & $8.61 \pm 0.09 \mathrm{Ba}$ \\
\hline \multirow{3}{*}{ Peonidin-3-O-glucoside } & L. brevis & $16.45 \pm 0.18 \mathrm{Ac}$ & $16.47 \pm 0.05 \mathrm{Bc}$ & $16.08 \pm 0.09 \mathrm{Ac}$ & $13.14 \pm 0.03 \mathrm{Ab}$ & $12.62 \pm 0.42 \mathrm{Bb}$ & $7.72 \pm 0.05 \mathrm{Aa}$ \\
\hline & L. acidophilus & $16.45 \pm 0.18 \mathrm{Ad}$ & $14.71 \pm 0.14 \mathrm{Ac}$ & $15.19 \pm 0.05 \mathrm{Acd}$ & $16.38 \pm 0.59 \mathrm{Bd}$ & $11.73 \pm 0.20 \mathrm{ABb}$ & $9.20 \pm 0.21 \mathrm{Ba}$ \\
\hline & O. oeni & $16.45 \pm 0.18 \mathrm{Ae}$ & $15.19 \pm 0.17 \mathrm{Ad}$ & $15.2 \pm 0.42 \mathrm{Ad}$ & $13.60 \pm 0.05 \mathrm{Ac}$ & $11.18 \pm 0.14 \mathrm{Ab}$ & $8.17 \pm 0.02 \mathrm{Aa}$ \\
\hline \multirow[t]{3}{*}{ Delphinidin-3-O-galactoside } & L. brevis & $15.07 \pm 0.03 \mathrm{Abcd}$ & $16.96 \pm 1.32 \mathrm{Bcd}$ & $18.13 \pm 0.95 \mathrm{Bd}$ & $12.33 \pm 0.35 \mathrm{Bb}$ & $14.11 \pm 0.83 \mathrm{Bbc}$ & $7.30 \pm 0.27 \mathrm{Aa}$ \\
\hline & L. acidophilus & $15.07 \pm 0.03 \mathrm{Ae}$ & $12.73 \pm 0.13 \mathrm{Ac}$ & $12.77 \pm 0.06 \mathrm{Ac}$ & $13.39 \pm 0.09 \mathrm{Cd}$ & $10.57 \pm 0.09 \mathrm{Ab}$ & $7.50 \pm 0.08 \mathrm{Aa}$ \\
\hline & O. oeni & $15.07 \pm 0.03 \mathrm{Ae}$ & $11.92 \pm 0.59$ Acd & $12.80 \pm 0.11 \mathrm{Ad}$ & $11.23 \pm 0.09 \mathrm{Ac}$ & $9.63 \pm 0.20 \mathrm{Ab}$ & $6.90 \pm 0.08 \mathrm{Aa}$ \\
\hline \multirow[t]{3}{*}{ Cyanidin-3-O-glucoside } & L. brevis & $14.72 \pm 0.17 \mathrm{Ac}$ & $17.30 \pm 0.36 \mathrm{Bd}$ & $18.05 \pm 0.36 \mathrm{Bd}$ & $14.43 \pm 0.09 \mathrm{Bc}$ & $12.04 \pm 0.65 \mathrm{Bb}$ & $6.39 \pm 0.12 \mathrm{Aa}$ \\
\hline & L. acidophilus & $14.72 \pm 0.17 \mathrm{Ac}$ & $14.56 \pm 0.10 \mathrm{Ac}$ & $14.63 \pm 0.23 \mathrm{Ac}$ & $15.59 \pm 0.52 \mathrm{Bc}$ & $11.80 \pm 0.17 \mathrm{Bb}$ & $7.85 \pm 0.04 \mathrm{Ba}$ \\
\hline & O. oeni & $14.72 \pm 0.17 \mathrm{Ad}$ & $14.86 \pm 0.54 \mathrm{Ad}$ & $14.57 \pm 0.23 \mathrm{Ad}$ & $13.10 \pm 0.04 \mathrm{Ac}$ & $9.87 \pm 0.09 \mathrm{Ab}$ & $6.48 \pm 0.16 \mathrm{Aa}$ \\
\hline \multirow[t]{3}{*}{ Petunidin-3-O-galactoside } & L. brevis & $3.71 \pm 0.12 \mathrm{Ab}$ & $4.24 \pm 0.03 \mathrm{Abc}$ & $5.13 \pm 0.12 \mathrm{Bc}$ & $4.26 \pm 0.10 \mathrm{Abc}$ & $4.04 \pm 0.44 \mathrm{Ab}$ & $2.10 \pm 0.06 \mathrm{Aa}$ \\
\hline & L. acidophilus & $3.71 \pm 0.12 \mathrm{Ab}$ & $4.62 \pm 0.05 \mathrm{Bc}$ & $4.34 \pm 0.08 \mathrm{Ac}$ & $4.65 \pm 0.07 \mathrm{Bc}$ & $3.30 \pm 0.06 \mathrm{Ab}$ & $2.60 \pm 0.18 \mathrm{Ba}$ \\
\hline & O. oeni & $3.71 \pm 0.12 \mathrm{Abc}$ & $4.62 \pm 0.08 \mathrm{Bd}$ & $4.18 \pm 0.15 \mathrm{Acd}$ & $4.27 \pm 0.10 \mathrm{ABd}$ & $3.55 \pm 0.13 \mathrm{Ab}$ & $2.24 \pm 0.06 \mathrm{ABa}$ \\
\hline
\end{tabular}


Table 1. Cont

\begin{tabular}{|c|c|c|c|c|c|c|c|}
\hline \multirow{2}{*}{ Compound (mg/L) } & \multirow{2}{*}{ Strain } & \multicolumn{6}{|c|}{ Time (Day) } \\
\hline & & 0 & 1 & 2 & 3 & 7 & 14 \\
\hline \multirow[t]{3}{*}{ Petunidin-3-O-arabinoside } & L. brevis & $3.55 \pm 0.01 \mathrm{Abc}$ & $3.90 \pm 0.08 \mathrm{Bcd}$ & $4.04 \pm 0.17 \mathrm{Bd}$ & $3.39 \pm 0.02 \mathrm{Bb}$ & $3.12 \pm 0.11 \mathrm{Bb}$ & $1.45 \pm 0.03 \mathrm{Aa}$ \\
\hline & L. acidophilus & $3.55 \pm 0.01 \mathrm{Ac}$ & $3.39 \pm 0.10 \mathrm{Ac}$ & $3.47 \pm 0.02 \mathrm{Ac}$ & $4.35 \pm 0.02 \mathrm{Cd}$ & $2.65 \pm 0.03 \mathrm{Ab}$ & $1.89 \pm 0.07 \mathrm{Ba}$ \\
\hline & O. oеni & $3.55 \pm 0.01 \mathrm{Ad}$ & $3.60 \pm 0.11 \mathrm{ABd}$ & $3.53 \pm 0.05 \mathrm{Ad}$ & $3.09 \pm 0.10 \mathrm{Ac}$ & $2.53 \pm 0.09 \mathrm{Ab}$ & $1.58 \pm 0.07 \mathrm{Aa}$ \\
\hline \multirow[t]{3}{*}{ Malvidin-3-O-arabinoside } & L. brevis & $2.14 \pm 0.12 \mathrm{Ad}$ & $1.90 \pm 0.06 \mathrm{Ad}$ & $2.10 \pm 0.05 \mathrm{Bd}$ & $1.59 \pm 0.02 \mathrm{Ac}$ & $1.17 \pm 0.07 \mathrm{Bb}$ & $0.50 \pm 0.01 \mathrm{Ba}$ \\
\hline & L. acidophilus & $2.14 \pm 0.12 \mathrm{Ad}$ & $1.81 \pm 0.02 \mathrm{Ac}$ & $1.94 \pm 0.05 \mathrm{Bcd}$ & $1.79 \pm 0.00 \mathrm{Bc}$ & $1.17 \pm 0.02 \mathrm{Bb}$ & $0.51 \pm 0.02 \mathrm{Ba}$ \\
\hline & O. oeni & $2.14 \pm 0.12 \mathrm{Ad}$ & $1.69 \pm 0.06 \mathrm{Ac}$ & $1.54 \pm 0.02 \mathrm{Ac}$ & $1.60 \pm 0.02 \mathrm{Ac}$ & $0.96 \pm 0.02 \mathrm{Ab}$ & $0.43 \pm 0.01 \mathrm{Aa}$ \\
\hline \multirow{3}{*}{ Total } & L. brevis & $331.13 \pm 1.34 \mathrm{Acd}$ & $372.39 \pm 10.13 \mathrm{Be}$ & $370.37 \pm 0.71$ Bde & $282.48 \pm 6.878 \mathrm{Ab}$ & $293.11 \pm 15.65 \mathrm{Bbc}$ & $172.23 \pm 3.56 \mathrm{Aa}$ \\
\hline & L. acidophilus & $331.13 \pm 1.34 \mathrm{Ae}$ & $301.24 \pm 3.58 \mathrm{Ac}$ & $312.61 \pm 3.1 \mathrm{Acd}$ & $318.82 \pm 2.31$ Bde & $245.82 \pm 0.83 \mathrm{Ab}$ & $188.88 \pm 3.94 \mathrm{Ba}$ \\
\hline & O. oeni & $331.13 \pm 1.34 \mathrm{Ae}$ & $301.82 \pm 7.91 \mathrm{Ad}$ & $307.44 \pm 3.06 \mathrm{Ad}$ & $273.90 \pm 2.17 \mathrm{Ac}$ & $226.68 \pm 4.65 \mathrm{Ab}$ & $173.71 \pm 1.48 \mathrm{Aa}$ \\
\hline
\end{tabular}

Data are mean \pm standard deviation of triplicate tests; Different letters in lower case indicate significant differences with time, whereas different letters in upper case represent significant difference in juice inoculated with different strains at the same sampling interval at $p<0.05$. 


\subsubsection{Non-Anthocyanin Phenolic Compounds}

A total of 26 non-anthocyanin phenolic compounds were detected in the juice before the bacteria inoculation (Table S4 and Figure 2). Flavonols appeared to be the dominant non-anthocyanin phenolic compound class. Generally, the contents of almost all compounds decreased after the inoculation with lactic acid bacteria.

The dominant phenolic acids in the original juice included chlorogenic acid, gallic acid, protocatechuic acid, and caffeic acid. These compounds represented more than $98 \%$ of the total phenolic acids content in the juice. Among the LAB, L. acidophilus had the strongest effect on the metabolism of protocatechuic and caffeic acids. For example, a remarkable decrease in the content of protocatechuic acid was observed already after one day from the incubation. A similar trend was also observed with caffeic acid. L. acidophilus did not, however, significantly metabolize the chlorogenic acid in the juice as the other two strains did.

A total of seven flavanols were detected, and epicatechin $(18.60 \mathrm{mg} / \mathrm{L})$ and procyanidin B2 $(5.85 \mathrm{mg} / \mathrm{L})$ were the most abundant flavanols (Table S4). During the incubation process, the level of epicatechin decreased more than $50 \%$ after 7 day of the inoculation, whereas the content of procyanidin B2 was less than $2 \mathrm{mg} / \mathrm{L}$ after the whole incubation process. The L. acidophilus inoculated juice exhibited higher level of the flavanols than the other two juices, indicating that L. brevis and O. oeni metabolized flavanols better than L. acidophilus.

The major flavonols in the juice included myricetin-3-O-galactoside, quercetin-3-O-glucuronide, quercetin-3-O-galactoside, syringetin-3-O-galactoside, and quercetin. These compounds were significantly degraded by the lactic acid bacteria (Table S4). For example, myricetin-3-O-galactoside decreased its content by approximately $20 \mathrm{mg} / \mathrm{L}$ in the juice after the incubation, and its evolution pattern was similar with the three LAB. Quercetin-3-O-galactoside and the free quercetin also decreased by approximately $30 \%$ throughout the incubation process. O. oeni showed a greater effect on the metabolism of these two flavonols than the other strains. Moreover, O. oeni and L. acidophilus showed a better capacity (faster consume speed) of catabolizing quercetin-3-O-glucuronide than L. brevis. The lowest level of the flavonols was found in the O. oeni sample, indicating that this strain might possess a better ability of consuming flavonols.

\subsection{Color Attributes}

A significant increase on the $\mathrm{L}^{*}$ value was observed in the juice inoculated with L. acidophilus and O. oeni since the first day of the incubation (Table 2). However, the L. brevis inoculated juice did not show a significant change on the $L^{*}$ value during the incubation period. The L. acidophilus inoculated juice exhibited a higher value on $\mathrm{L}^{*}$ than the juice with $O$. oeni after two days of the incubation. The significant alteration of the $\mathrm{a}^{*}$ (less red) value in the juice inoculated with L. brevis was observed only at the end of the incubation. However, the other two strains resulted in a consistent decrease in the $\mathrm{a}^{*}$ (less red) value throughout the 14 days. Eventually, the three juices displayed the similar $\mathrm{a}^{*}$ value (similar redness) after the incubation. The $b^{*}$ value showed an increase (more yellow) in the L. brevis inoculated juice at the first incubation day, followed by a decrease (less yellow). Its value continued to decrease (less yellow) in the juice inoculated with the other two strains after the inoculation. Moreover, its decrease was more rapid in the O. oeni inoculated juice. After the incubation, a negative $b^{*}$ value was observed in the $O$. oeni inoculated juice, indicating that it was significantly greener than the other juices. A significant color difference (the $\Delta \mathrm{E}^{*}$ value) was observed in the $O$. oeni inoculated juice since the first day of the incubation, and the dramatic color difference remained during the whole process. The significant color difference started to be observed in the L. acidophilus inoculated juice after 7 days of the incubation, while the variation of the color difference in the juice inoculated with L. brevis was the most stable among the juices during the fermentation. 
Table 2. Values of color attributes in bog bilberry juice after inoculating with three lactic acid bacteria strains in 14 days.

\begin{tabular}{|c|c|c|c|c|c|c|c|}
\hline \multirow{2}{*}{ Compound } & \multirow{2}{*}{ Strain } & \multicolumn{6}{|c|}{ Time (Day) } \\
\hline & & 0 & 1 & 2 & 3 & 7 & 14 \\
\hline \multirow{3}{*}{$\mathrm{L}^{*}$ value } & L. brevis & $46.34 \pm 1.18 \mathrm{Aa}$ & $44.95 \pm 0.94 \mathrm{Aa}$ & $46.69 \pm 1.54 \mathrm{Aa}$ & $45.97 \pm 0.77 \mathrm{Aa}$ & $46.41 \pm 0.65 \mathrm{Aa}$ & $51.02 \pm 1.94 \mathrm{Ab}$ \\
\hline & L. acidophilus & $46.34 \pm 1.18 \mathrm{Aa}$ & $49.05 \pm 0.47 \mathrm{Bb}$ & $49.14 \pm 1.56 \mathrm{ABb}$ & $49.14 \pm 0.93 \mathrm{Bb}$ & $50.29 \pm 0.90 \mathrm{Bb}$ & $51.00 \pm 0.38 \mathrm{Ab}$ \\
\hline & O. oеni & $46.34 \pm 1.18 \mathrm{Aa}$ & $51.90 \pm 0.51 \mathrm{Cbc}$ & $51.55 \pm 0.70 \mathrm{Cb}$ & $51.10 \pm 0.98 \mathrm{Cb}$ & $52.31 \pm 0.14 \mathrm{Cbc}$ & $53.04 \pm 0.64 \mathrm{Ac}$ \\
\hline \multirow{3}{*}{$a^{*}$ value } & L. brevis & $60.34 \pm 0.02 \mathrm{Ab}$ & $60.66 \pm 0.06 \mathrm{Cb}$ & $60.47 \pm 0.17 \mathrm{Cb}$ & $60.37 \pm 0.12 \mathrm{Cb}$ & $60.06 \pm 0.05 \mathrm{Cb}$ & $58.71 \pm 1.01 \mathrm{Ac}$ \\
\hline & L. acidophilus & $60.34 \pm 0.02 \mathrm{Ac}$ & $60.19 \pm 0.05 \mathrm{Bc}$ & $60.06 \pm 0.28 \mathrm{Bc}$ & $59.92 \pm 0.16 \mathrm{Bbc}$ & $59.37 \pm 0.14 \mathrm{Bab}$ & $58.85 \pm 0.72 \mathrm{Aa}$ \\
\hline & O. oeni & $60.34 \pm 0.02 \mathrm{Ad}$ & $59.61 \pm 0.15 \mathrm{Ac}$ & $59.55 \pm 0.11 \mathrm{Ac}$ & $59.40 \pm 0.20 \mathrm{Ac}$ & $58.69 \pm 0.17 \mathrm{Ab}$ & $57.56 \pm 0.38 \mathrm{Aa}$ \\
\hline \multirow{3}{*}{$b^{*}$ value } & L. brevis & $2.24 \pm 0.71 \mathrm{Ab}$ & $4.64 \pm 0.29 \mathrm{Bc}$ & $4.14 \pm 0.80 \mathrm{Bc}$ & $3.62 \pm 0.22 \mathrm{Bc}$ & $2.50 \pm 0.15 \mathrm{Bb}$ & $-0.60 \pm 0.90 \mathrm{Ac}$ \\
\hline & L. acidophilus & $2.24 \pm 0.71 \mathrm{Ab}$ & $2.68 \pm 0.26 \mathrm{Ab}$ & $2.60 \pm 0.83 \mathrm{Ab}$ & $2.22 \pm 0.44 \mathrm{Ab}$ & $1.55 \pm 0.68 \mathrm{Aab}$ & $0.73 \pm 1.16 \mathrm{Aa}$ \\
\hline & O. oeni & $2.24 \pm 0.71 \mathrm{Ac}$ & $2.06 \pm 0.48 \mathrm{Ac}$ & $2.00 \pm 0.25 \mathrm{Ac}$ & $1.61 \pm 0.39 \mathrm{Ac}$ & $0.61 \pm 0.44 \mathrm{Ab}$ & $-0.47 \pm 0.38 \mathrm{~A}$ \\
\hline \multirow{3}{*}{$\Delta \mathrm{E}^{*}$ value } & L. brevis & - & $2.85 \pm 0.70 \mathrm{Ab}$ & $2.73 \pm 0.54 \mathrm{Aab}$ & $1.55 \pm 0.38 \mathrm{Aab}$ & $0.64 \pm 0.26 \mathrm{Aa}$ & $5.75 \pm 2.20 \mathrm{Ac}$ \\
\hline & L. acidophilus & - & $2.76 \pm 0.46 \mathrm{Aa}$ & $2.92 \pm 1.56 \mathrm{Aa}$ & $2.86 \pm 0.96 \mathrm{Aa}$ & $4.17 \pm 0.84 \mathrm{Bab}$ & $5.21 \pm 0.73 \mathrm{Ab}$ \\
\hline & O. oeni & - & $5.63 \pm 0.55 \mathrm{Bab}$ & $5.28 \pm 0.71 \mathrm{Bab}$ & $4.90 \pm 1.05 \mathrm{Ba}$ & $6.42 \pm 0.22 \mathrm{Cb}$ & $7.75 \pm 0.81 \mathrm{Cc}$ \\
\hline
\end{tabular}

Data are mean \pm standard deviation of triplicate tests; Different letters in lower case indicate significant differences with time, whereas different letters in upper case represent significant difference in juice inoculated with different strains at the same sampling interval at $p<0.05$. $L^{*}$ represents brightness, larger the data of $L^{*}$ is, lighter the color will be. $A^{*}$ represents the color of red and green, larger the data of $\mathrm{a}^{*}$ is, redder the color will be, otherwise, greener it will be. $\mathrm{B}^{*}$ represents the color of yellow and blue, larger the data of $\mathrm{b}^{*}$ is, yellower the color will be, otherwise, bluer it will be. $\Delta \mathrm{E}^{*}$ describes the degree of deviation from the original wine color, larger the data of $\Delta \mathrm{E}^{*}$ is, greater the color variation will be 


\subsection{Multivariate Statistical Analysis}

A total of 75 chemical variables (not including the total amount index and color index), including 2 reducing sugars, 6 organic acids, 10 anthocyanins, 31 nitrogen-containing compounds, 7 phenolic acids, 7 flavanols and 12 flavonols, were detected and analyzed in the juices inoculated with the three different bacteria, respectively (Figure 3 and Tables S2-S5). The multivariate statistical analyses, including the principal component analyze, clustering-heatmap, and two-way ANOVA were used to analyze these data (Figures 2 and 4 ).

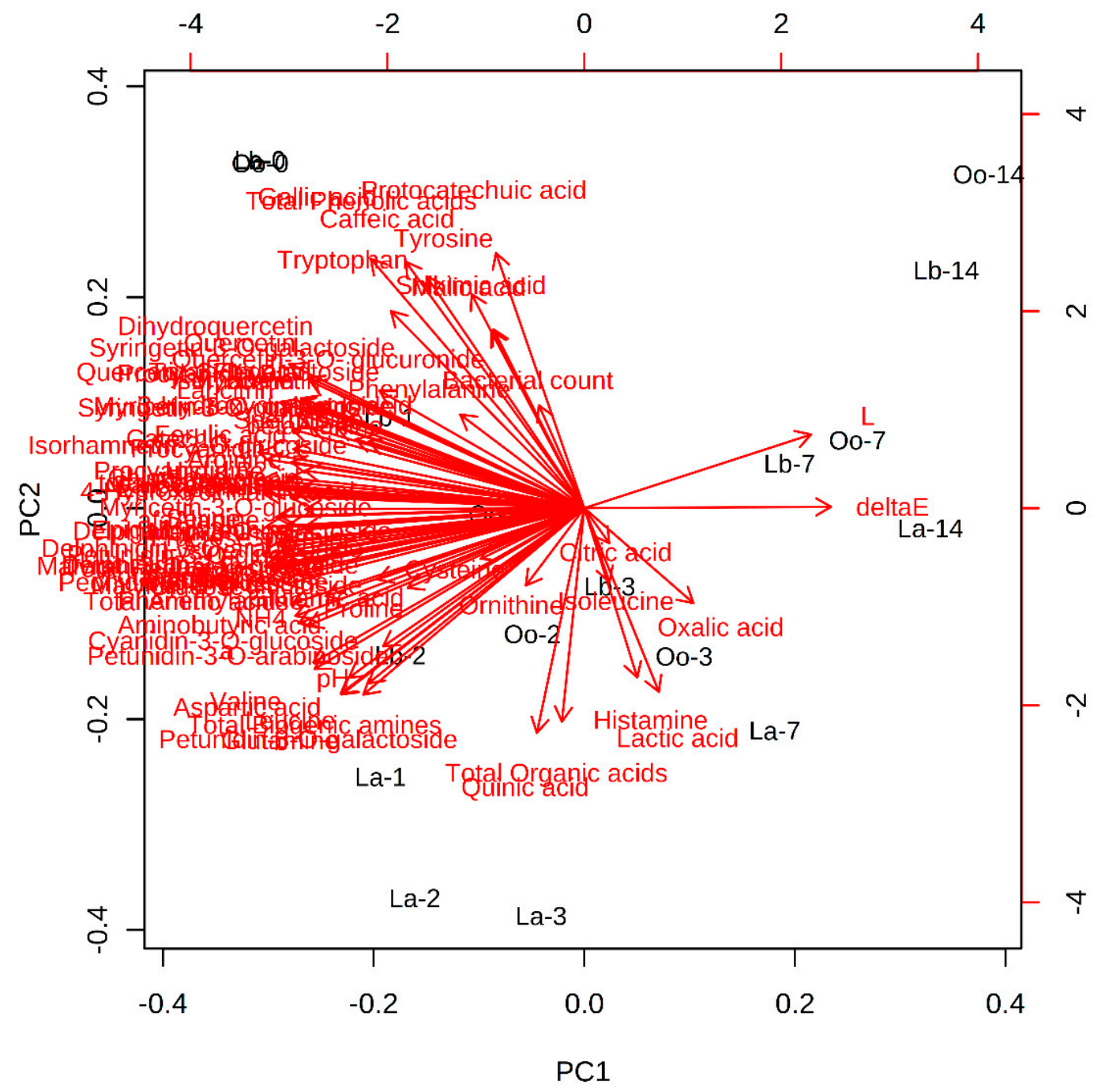

Figure 4. Principal component analysis of all compounds $(n=85)$ in the bog bilberry juices in fermented for 0-14 days using lactic acid bacteria strains (Lb Lactobacillus brevis, Oo Oenococcus oeni, La Lactobacillus acidophilus).

The first two components shown in Figure 4 represented $58.8 \%$ and $11.3 \%$ of the total variance. The samples were mainly divided along the first principal component (PC1) based on the inoculation time, whereas the second principal component (PC2) divided each strain (Figure 4). The L. acidophilus inoculated juice samples were gathered in the bottom of PC2, while the juices inoculated with O. oeni, and L. brevis were in the upper part of PC2. Moreover, most of the compounds are located close to the 0- or 1-day samples on left side of the biplot along the PC1. Catechin, procyanidin B2, malvidin-3-O-arabinoside and total flavanols are the variables with the most contribution to these samples on the left on PC1. As the time and fermentations proceeded, the content of most the components decreased along the PC1. 
The heatmap and clustering analysis divided the evolution of all the compounds into 4 patterns (Figure 2). Pattern 1 included three phenolic acids, two amino acids, one flavonol and two organic acids. The contents of these eight compounds decreased over time after the inoculation in all the three LAB strains. The decreases were the fastest in the L. acidophilus inoculated samples. The second pattern (2) included three amino acids and four organic acids. The compounds in this pattern showed increases at least with one strain. Pattern 3 included three phenolic acids, seven amino acids, nearly all the flavonols, all the flavanols and two biogenic amines, whereas pattern 4 included one phenolic acid, 11 amino acids, all the reducing sugars, most of the biogenic amines and all the anthocyanins. In addition, although different from compounds in pattern 2, the compounds included in patterns 3 and 4 showed decreases along the time, and the speed of the decrease in pattern 3 was faster than this in pattern 4 . Moreover, the compounds in patterns 3 and 4 showed similar decreasing trend among different strains. It could be intuitively found that most components had a significant downward trend after inoculation of lactic acid bacteria. Only a small fraction of the components had a floating or rising trend. Surprisingly, most of the flavonols and all the flavanols belonged to pattern 3. Nearly all the biogenic amines, all the reducing sugars and anthocyanins were included in pattern 4 . These indicated that there might be some correlations between these components in each pattern.

A two-way ANOVA (strain and time as the main effects) was applied in order to further highlight the incidence of these factors. The strains were found to affect 23 components, whereas the inoculation time affected 73 components $(p<0.05)$. Meanwhile, 20 components were affected by both the time and strain $(p<0.05)$. However, the remaining 13 components, such as malic acid, were independent of both factors (include total amount index and color index).

\section{Discussion}

The optimal growth $\mathrm{pH}$ condition for L. brevis and O. oeni has been reported at 5.0 and 4.8 , respectively $[43,44]$. In the present study, these two strains showed a rapid decline on their growth after being inoculated into the juice. Compared to these two lactic acid bacteria, L. acidophilus, a homofermentative strain, has been reported to exhibit the resistance against low $\mathrm{pH}$ condition through regulating its cytoplasmic $\mathrm{pH}[45,46]$. Its cytoplasmic $\mathrm{pH}$ was accommodated to be neutral when this lactic acid bacterium encountered the extreme $\mathrm{pH}$ condition ( $\mathrm{pH}$ below 3.5). A good growth of L. acidophilus has been observed in the pomegranate juice after a 24-h lag phase [47]. The low $\mathrm{pH}$ condition, such as in the bog bilberry juice, may potentially destroy the bacterial cells and inhibit the synthesis of enzymes [48]. In the present study, L. acidophilus showed a good resisting capacity in the low $\mathrm{pH}$ condition by maintaining a higher growth rate in the first three days of the incubation. Nevertheless, L. brevis and O. oeni showed a better adaption in the bog bilberry juice after seven days compared to L. acidophilus.

The low $\mathrm{pH}$ condition may also exert negative effects on the glucose consumption of lactic acid bacteria through inhibiting the glucose metabolism and transport [49]. Rapid sugar consumptions have been observed in juices with higher $\mathrm{pH}$ conditions in the presence of lactic acid bacteria. Specifically, carrot juice and tomato juices have been reported to possess $\mathrm{pH}$ values of 5.78 and 4.38 , respectively, and a rapid sugar consumption was reported after inoculation in these juices [7]. However, a slow consumption of sugars was observed in pineapple juice ( $\mathrm{pH}$ 3.64) and cherry juice ( $\mathrm{pH} 3.95)$ after inoculation [7]. The evolution of sugars in this study was found to be as similar as that in pomegranate juice inoculated with L. acidophilus since pomegranate juice had a similar $\mathrm{pH}$ value as bog bilberry juice (3.1 versus 2.6).

Lactic acid bacteria are considered to have the capacities to accumulate organic acids, and lactic acid is the major factor enhancing the level of organic acids in juices [50]. Lactic acid has been regarded as the primary metabolite formed by lactic acid bacteria [51]. However, the level of organic acids in the present study did not significantly increase after the inoculation of these lactic acid bacteria. Lactic acid was only accumulated in the L. acidophilus inoculated juice. This might be because the low $\mathrm{pH}$ condition in bog bilberry juice might alter the fatty acid biosynthesis in pyruvate metabolism, glycolysis related 
enzymes activity, and/or transcriptional regulation network [52]. Citric acid is a potential carbon source for some lactic acid bacteria when it is present in the juice in high concentrations $[47,53]$. In this study, the citric acid content decreased in the O. oeni inoculated juice after 1 day of the incubation. This might be because of the relatively low content of citric acid in the bog bilberry. The content of malic acid in the juice did not significantly change with these strains. Only the inoculation of L. acidophilus resulted in a concentration fluctuation of malic acid in the juice.

Branched-chain amino acids have been reported to be efficiently consumed in cherry and pineapple juices by lactic acid bacteria, and such consumptions could increase the concentration of $\gamma$-aminobutyric acid $[4,7]$. In addition, the catabolism of the branched-chain amino acids with lactic acid bacteria could release numerous volatile compounds, and the released volatiles could play important roles in affecting the aroma complexity of the products [6]. In this study, all the lactic acid bacteria consumed valine and leucine in the bog bilberry juice, whereas isoleucine was only utilized by O. oeni. These factors indicated that different lactic acid bacteria possess their own preferences in consuming amino acids [54]. Tyramine and histidine are essential amino acids for the growth of Lactobacillus delbrueckii subsp. lactis [55]. The content of these two amino acids decreased in this study. Two pathways are involved in the metabolism of tyramine and histidine: Transamination and decarboxylation for tyramine and deamination and decarboxylation for histidine [6]. Additionally, ornithine, $\gamma$-aminobutyric acid and ammonium were found to be accumulated in the juices at the beginning of the inoculation, which might result from the acid tolerance of lactic acid bacteria [56]. It should be noted that the evolution of ornithine in juice may be used as an indicator for differentiating lactic acid bacteria in further research. In this study, the highest concentration of ornithine was found in the O. oeni inoculated bog bilberry juice.

Some of the biogenic amines could induce the allergic reactions when these are excessively accumulated [57]. Lactic acid bacteria have been reported to have the ability of producing biogenic amines through the amino acid decarboxylation after inoculation [57]. The amino acid oxidase in $\mathrm{LAB}$ can further metabolize biogenic amines to support the growth of bacteria $[57,58]$. In this study, the contents of cadaverine, putrescine, and phenethylamine decreased after the incubation period. This might result in an improvement on the juice quality through reducing the concern of the potential threat of biogenic amines to human health.

Phenolic compounds potentially have an inhibitory influence on the growth and viability of lactic acid bacteria [15]. Meanwhile, LAB could metabolize phenolic compounds through hydrolysis, reduction reactions, and/or decarboxylation [59]. In this study, almost all the phenolic compounds showed a decrease on the content in the juice during the incubation process (Table S4). For example, the glycosylated flavonols were hydrolyzed to yield sugar moieties and aglycones due to glycosidases released from the LAB. The released sugar moieties could be further consumed by these bacteria as the carbohydrate source $[15,47]$. Interestingly, the content of protocatechuic acid, gallic acid, and caffeic acid in the L. acidophilus inoculated juice was significantly lower than that in the other juices at the end of the incubation. It has been reported that the metabolism of phenolic compounds after inoculation could improve the regeneration of $\mathrm{NAD}^{+}$, an important electron acceptor in energy metabolism [60]. Lactic acid was accumulated to the juice inoculated only with L. acidophilus, and $\mathrm{NAD}^{+}$was also regenerated during the lactic acid production [35]. The inoculation of the lactic acid bacteria resulted in a decrease on the content of the total and individual anthocyanins in the bog bilberry juice. Our result was consistent with the previous study [61]. Moreover, some lactic acid bacteria have been reported to possess the capacity of converting anthocyanins into other bioactive phenolic compounds, such as gallic acid and protocatechuic acid [62]. These phenolic compounds could further interact with anthocyanins to form polymerized and/or copigmented anthocyanins, reducing the concentration of anthocyanins in juice [10].

In the CIEL*a*b* assay, the $L^{*}$ value refers to the color intensity and a high $L^{*}$ value represents a weak color density. The bog bilberry juice inoculated with L. brevis contained a consistent $L^{*}$ value during the incubation. However, the inoculation of L. acidophilus and O. oeni resulted in an increase on 
the $\mathrm{L}^{*}$ value in the juice (Table 2). These indicated that anthocyanins in the L. acidophilus and O. oeni inoculated juices might experience the polymerization, reducing the intensity of the juice color [63]. The $a^{*}$ value decreased in these bog bilberry juices, indicating that the color of the juices changed from the original red towards more greenish [64]. This color transition might result from the metabolism of anthocyanins during the incubation. The polymeric pigments synthesized from anthocyanins could also result in the color shift in the juice [19]. Similarly, the significant change on the $b^{*}$ value in the O. oeni inoculated juice might be caused by the accumulation of acylated anthocyanins in the juice [13]. The color difference $\left(\Delta \mathrm{E}^{*}\right)$ refers to the perceptible color change of the juice in comparison with the original juice. It has been announced that the $\Delta \mathrm{E}^{*}$ value above 3.0 indicated an obvious color difference between the samples judged by the human eyes [19]. In the present study, the O. oeni inoculated juice showed the most obvious change in the color, whereas the inoculation of L. brevis delayed the color change of the juice. Similar results were also observed in red and green smoothies after inoculation of lactic acid bacteria [65].

\section{Conclusions}

Three strains of lactic acid bacteria, including L. brevis, L. acidophilus and O. oeni, were inoculated into bog bilberry and they resulted in significant changes in the juice composition. The slow decreases in the sugar contents were observed in these juices, and the consumptions of sugars by these strains in the juice were similar. The juices displayed a significant decrease on the amino acid content. Moreover, tyramine, cadaverine, putrescine, and phenylethylamine decreased in the juices after incubation. No significant content alteration in organic acids was observed in these juices and lactic acid was only accumulated in the L. acidophilus inoculated juice. A significant content decrease was also observed to total phenolic acids, total flavonols, total flavan-3-ols, and individual phenolic compounds in these juices. The L. brevis inoculated juice contained higher concentrations of phenolic acids and flavonols, whereas the juice inoculated with L. acidophilus exhibited a higher level of flavanols. The anthocyanin content decreased in these juices after the incubation, and the L. acidophilus inoculated juice displayed the highest level. The color attributes $\mathrm{a}^{*}$ and $\mathrm{b}^{*}$ showed a decrease in the juice inoculated with L. acidophilus and O. oeni. However, an increase on $\mathrm{L}^{*}$ was observed in these juices. No significant alterations on these color attributes were observed in the juice inoculated with L. brevis. Taking all the factors into consideration, O. oeni had the best environmental adaptability and biogenic amine lowering ability with a strong influence on the color of the juice. Although L. acidophilus grew well in the early stage, its environmental adaptability was weak with the consistent decrease of its growth rate after inoculation. L. brevis had weaker environmental adaptability and biogenic amine lowering ability than O. oeni. However, it had less influence on the color of the juice. Therefore, compared to O. oeni and L. acidophilus, L. brevis is more suitable to inoculate into juice with low $\mathrm{pH}$. Further studies with the strains are needed to optimize their growth in the bog bilberry juice matrix in order to develop novel fermented beverages from the berry without extensive losses of various health-promoting components, such as anthocyanins.

Supplementary Materials: The following are available online at http://www.mdpi.com/2304-8158/8/10/430/s1, Table S1: Values of bacterial growth ratio in bog bilberry juice after inoculating with three lactic acid bacteria strains in 14 days, Table S2: Content of reducing sugar, organic acid and $\mathrm{pH}$ in bog bilberry juice inoculated with three lactic acid bacteria strains in 14 days, Table S3: Content of amino acids, ammonium ion, and biogenic amines in bog bilberry juice inoculated with three lactic acid bacteria strains in 14 days, Table S4: Content of phenolic acids, flavonols, flavanols, and anthocyanins in bog bilberry juice inoculated with three lactic acid bacteria strains in 14 days.

Author Contributions: B.Z. (Bolin Zhang) designed the study. X.O. and Y.C. performed the laboratory work. Y.C. and X.L. analyzed the data. Y.C., X.O., and Y.S. wrote the manuscript. B.Z. (Bolin Zhang), B.Z. (Baoqing Zhu), H.Z. and O.L. provided some ideas and revised the manuscript. All authors read and approved the final manuscript.

Funding: This study was funded by the Key Laboratory of Viticulture and Enology, Ministry of Agriculture (No. KLVE201701). 
Acknowledgments: The authors thanked Changqing Duan in the Center of Viticulture and Enology at the China Agricultural University for the help on the phenolic composition analysis.

Conflicts of Interest: The authors declare no conflicts of interest.

\section{References}

1. Di Cagno, R.; Coda, R.; De Angelis, M.; Gobbetti, M. Exploitation of vegetables and fruits through lactic acid fermentation. Food Microbiol. 2013, 33, 1-10. [CrossRef] [PubMed]

2. Parvez, S.; Malik, K.; Kang, S.; Kim, H. Probiotics and their fermented food products are beneficial for health. J. Appl. Microbiol. 2016, 100, 1171-1185. [CrossRef] [PubMed]

3. Zhao, L.L.; Wei, J.Y.; Zhao, H.F.; Zhu, B.Q.; Zhang, B.L. Detoxification of cancerogenic compounds by lactic acid bacteria strains. Crit. Rev. Food Sci. Nutr. 2017, 58, 2727-2742.

4. Di Cagno, R.; Filannino, P.; Gobbetti, M. Vegetable and Fruit Fermentation by Lactic Acid Bacteria; John Wiley \& Sons, Ltd.: Hoboken, NJ, USA, 2015.

5. Di Cagno, R.; Surico, R.F.; Paradiso, A.; De Angelis, M.; Salmon, J.C.; Buchin, S.; De Gara, L.; Gobbetti, M. Effect of autochthonous lactic acid bacteria starters on health-promoting and sensory properties of tomato juices. Int. J. Food Microbiol. 2009, 128, 473-483. [CrossRef] [PubMed]

6. Fernández, M.; Zúñiga, M. Amino acid catabolic pathways of lactic acid bacteria. Crit. Rev. Microbiol. 2006, 32, 155. [CrossRef] [PubMed]

7. Filannino, P.; Cardinali, G.; Rizzello, C.G.; Buchin, S.; Angelis, M.D.; Gobbetti, M.; Di Cango, R. Metabolic responses of Lactobacillus plantarum strains during fermentation and storage of vegetable and fruit juices. Appl. Environ. Microbiol. 2014, 80, 2206-2215. [CrossRef] [PubMed]

8. Jing, P.; Song, L.H.; Shen, S.H.; Zhao, S.J.; Pang, J.; Qian, B.J. Characterization of phytochemicals and antioxidant activities of red radish brines during lactic acid fermentation. Molecules 2014, 19, 9675-9688. [CrossRef] [PubMed]

9. Zafra-Stone, S.; Yasmin, T.; Bagchi, M.; Chatterjee, A.; Vinson, J.A.; Bagchi, D. Berry anthocyanins as novel antioxidants in human health and disease prevention. Mol. Nutr. Food Res. 2007, 51, 675-683. [CrossRef] [PubMed]

10. Francis, F.J.; Markakis, P.C. Food colorants: Anthocyanins. Crit. Rev. Food Sci. Nutr. 1989, $28,273-314$. [CrossRef]

11. Kwaw, E.; Ma, Y.; Tchabo, W.; Apaliya, M.T.; Wu, M.; Sackey, A.S.; Xiao, L.L.; Tahir, H.E. Effect of lactobacillus strains on phenolic profile, color attributes and antioxidant activities of lactic-acid-fermented mulberry juice. Food Chem. 2018, 250, 148-154. [CrossRef]

12. Rustioni, L.; Bedgood, D.R.; Failla, O.; Prenzler, P.D.; Robards, K. Copigmentation and anti-copigmentation in grape extracts studied by spectrophotometry and post-column-reaction HPLC. Food Chem. 2012, 132, 2194-2201. [CrossRef]

13. Rein, M.J.; Marina, H. Stability and enhancement of berry juice color. J. Agric. Food Chem. 2004, 52, $3106-3114$. [CrossRef] [PubMed]

14. Kopjar, M.; JakŠIĆ, K.; PiliŽOta, V. Influence of sugars and chlorogenic acid addition on anthocyanin content, antioxidant activity and color of blackberry juice during storage. J. Food Process. Preserv. 2012, 36, 545-552. [CrossRef]

15. Rodriguez, H.; Curiel, J.A.; Landete, J.M.; de las Rivas, B.; Lopez de Felipe, F.; Gomez-Cordoves, C.; Mancheno, J.M.; Munoz, R. Food phenolics and lactic acid bacteria. Int. J. Food Microbiol. 2009, 132, 79-90. [CrossRef] [PubMed]

16. Christensen, J.E.; Dudley, E.G.; Pederson, J.A.; Steele, J.L. Peptidases and amino acid catabolism in lactic acid bacteria. Antonie Leeuwenhoek 1999, 76, 217-246. [CrossRef] [PubMed]

17. Santos, M.H.S. Biogenic amines: Their importance in foods. Int. J. Food Microbiol. 1996, 29, 213-231. [CrossRef]

18. Wang, L.J.; Su, S.; Wu, J.; Du, H.; Li, S.S.; Huo, J.W.; Zhang, Y.; Wang, L.S. Variation of anthocyanins and flavonols in Vaccinium uliginosum berry in Lesser Khingan Mountains and its antioxidant activity. Food Chem. 2014, 160, 357-364. [CrossRef]

19. Liu, S.X.; Yang, H.Y.; Li, S.Y.; Zhang, J.Y.; Li, T.; Zhu, B.Q.; Zhang, B.L. Polyphenolic compositions and chromatic characteristics of bog bilberry syrup wines. Molecules 2015, 20, 19865-19877. [CrossRef] 
20. Colak, N.; Torun, H.; Gruz, J.; Strnad, M.; Hermosin-Gutierrez, I.; Hayirlioglu-Ayaz, S.; Ayaz, F.A. Bog bilberry phenolics, antioxidant capacity and nutrient profile. Food Chem. 2016, 201, 339-349. [CrossRef]

21. Kim, Y.H.; Bang, C.Y.; Won, E.K.; Kim, J.P.; Choung, S.Y. Antioxidant activities of Vaccinium uliginosum L. extract and its active components. J. Med. Food 2009, 12, 885-892. [CrossRef]

22. Ames, B.N.; Shigenaga, M.K.; Hagen, T.M. Oxidants, antioxidants, and the degenerative diseases of aging. Proc. Natl. Acad. Sci. USA 1993, 90, 7915-7922. [CrossRef] [PubMed]

23. Han, E.K.; Kwon, H.S.; Shin, S.G.; Choi, Y.H.; Kang, I.J.; Chung, C.K. Biological effect of Vaccinium uliginosum L. on STZ-induced diabetes and lipid metabolism in rats. J. Korean Soc. Food Sci. Nutr. 2012, 41, 1727-1733. [CrossRef]

24. Chen, C.; Lu, Y.; Yu, H.; Chen, Z.; Tian, H. Influence of 4 lactic acid bacteria on the flavor profile of fermented apple juice. Food Biosci. 2019, 27, 30-36. [CrossRef]

25. Markkinen, N.; Laaksonen, O.; Nahku, R.; Kuldjarv, R.; Yang, B. Impact of lactic acid fermentation on acids, sugars, and phenolic compounds in black chokeberry and sea buckthorn juices. Food Chem. 2019, 286, $204-215$. [CrossRef] [PubMed]

26. Park, J.B.; Lim, S.H.; Sim, H.S.; Park, J.H.; Kwon, H.J.; Nam, H.S.; Kim, M.D.; Baek, H.H.; Ha, S.J. Changes in antioxidant activities and volatile compounds of mixed berry juice through fermentation by lactic acid bacteria. Food Sci. Biotechnol. 2017, 26, 441-446. [CrossRef] [PubMed]

27. Ricci, A.; Cirlini, M.; Levante, A.; Dall'Asta, C.; Galaverna, G.; Lazzi, C. Volatile profile of elderberry juice: Effect of lactic acid fermentation using L. plantarum, L. rhamnosus and L. casei strains. Food Res. Int. 2018, 105, 412-422. [CrossRef] [PubMed]

28. Wei, M.; Wang, S.Y.; Gu, P.; Ouyang, X.Y.; Liu, S.X.; Li, Y.Q.; Zhang, B.L.; Zhu, B.Q. Comparison of physicochemical indexes, amino acids, phenolic compounds and volatile compounds in bog bilberry juice fermented by Lactobacillus plantarum under different $\mathrm{pH}$ conditions. J. Food Sci. Technol. 2018, 55, 2240-2250. [CrossRef]

29. Sanders, M.E.; Klaenhammer, T.R. Invited review: The scientific basis of Lactobacillus acidophilus NCFM functionality as a probiotic. J. Dairy Sci. 2001, 84, 319-331. [CrossRef]

30. Collins, J.K.; Thornton, G.; Sullivan, G.O. Selection of probiotic strains for human applications. Int. Dairy J. 1998, 8, 487-490. [CrossRef]

31. Kim, J.Y.; Lee, M.Y.; Ji, G.E.; Lee, Y.S.; Hwang, K.T. Production of gamma-aminobutyric acid in black raspberry juice during fermentation by Lactobacillus brevis GABA100. Int. J. Food Microbiol. 2009, 130, 12-16. [CrossRef]

32. Alexandre, H.; Costello, P.J.; Remize, F.; Guzzo, J.; Guilloux-Benatier, M. Saccharomyces cerevisiae-Oenococcus oeni interactions in wine: Current knowledge and perspectives. Int. J. Food Microbiol. 2004, 93, 141-154. [CrossRef] [PubMed]

33. Ling, D.W.; Dong, X.Z. Characterization and Experimental Methods of Lactic Acid Bacteria; China Light Industry Press: Beijing, China, 1999.

34. De Man, J.C.; Rogosa, M.; Sharpe, M.E. A medium for the cultivation of Lactobacilli. J. Appl. Bacteriol. 1960, 23, 130-135. [CrossRef]

35. Fugelsang, K.C.; Edwards, C.G. Wine Microbiology: Practical Applications and Procedures; Springer: Berlin/Heidelberg, Germany, 2007.

36. Wei, M.; Gu, P.; Li, C.J.; Yang, H.Y.; Liu, S.X.; Zhang, J.Y.; Yan, Z.X.; Zhang, B.L.; Zhu, B.Q. Determination of 7 organic acids in Vaccinium uliginosum products by HPLC. China Brew. 2014, 33, 145-148.

37. Welman, A.D.; Maddox, I.S. Exopolysaccharides from lactic acid bacteria: Perspectives and challenges. Trends Biotechnol. 2003, 21, 269-274. [CrossRef]

38. Li, J.C.; Li, S.Y.; He, F.; Yuan, Z.Y.; Liu, T.; Reeves, M.J.; Duan, C.Q. Phenolic and chromatic properties of beibinghong red ice wine during and after vinification. Molecules 2016, 21, 431. [CrossRef] [PubMed]

39. Li, R.; Wang, P.; Guo, Q.Q.; Wang, Z.Y. Anthocyanin composition and content of the Vaccinium uliginosum berry. Food Chem. 2011, 125, 116-120. [CrossRef]

40. Gao, Y.; Tian, Y.; Liu, D.; Li, Z.; Zhang, X.X.; Li, J.M.; Huang, J.H.; Wang, J.; Pan, Q.H. Evolution of phenolic compounds and sensory in bottled red wines and their co-development. Food Chem. 2015, 172, 565-574. [CrossRef] [PubMed] 
41. Lee, J.; Durst, R.W.; Wrolstad, R.E. Determination of total monomeric anthocyanin pigment content of fruit juices, beverages, natural colorants, and wines by the $\mathrm{pH}$ differential method: Collaborative study. J. AOAC Int. 2005, 88, 1269-1278.

42. Tarján, V.; Jánossy, G. The role of biogenic amines in foods. Mol. Nutr. Food Res. 1978, 22, 285-289. [CrossRef]

43. Dicks, L.M.T.; Dellaglio, F.; Collins, M.D. Proposal to reclassify Leuconostoc oenos as Oenococcus oeni [corrig.] gen. nov.; comb. nov. Int. J. Syst. Bacteriol. 1995, 45, 395-397. [CrossRef]

44. Moreno-Arribas, V.; Lonvaud-Funel, A. Tyrosine decarboxylase activity of Lactobacillus brevis IOEB 9809 isolated from wine and L. brevis ATCC 367. FEMS Microbiol. Lett. 1999, 180, 55-60. [CrossRef] [PubMed]

45. Conway, P.L.; Gorbach, S.L.; Goldin, B.R. Survival of lactic acid bacteria in the human stomach and adhesion to intestinal cells. J. Dairy Sci. 1987, 70, 1-12. [CrossRef]

46. Kashket, E.R. Bioenergetics of lactic acid bacteria: Cytoplasmic pH and osmotolerance. FEMS Microbiol. Lett. 1987, 46, 233-244. [CrossRef]

47. Mousavi, Z.; Mousavi, M.; Razavi, S.H.; Hadinejad, M.; Emam-Djomeh, Z.; Mirzapour, M. Effect of fermentation of pomegranate juice by Lactobacillus plantarum and Lactobacillus acidophilus on the antioxidant activity and metabolism of sugars, organic acids and phenolic compounds. Food Biotechnol. 2013, 27, 1-13. [CrossRef]

48. Harvey, R.J. Damage to streptococcus lactis resulting from growth at low pH. J. Bacteriol. 1965, 90, 1330-1336. [PubMed]

49. Carvalho, A.L.; Turner, D.L.; Fonseca, L.L.; Solopova, A.; Catarino, T.; Kuipers, O.P.; Voit, E.O.; Neves, A.R.; Santos, H. Metabolic and transcriptional analysis of acid stress in Lactococcus lactis, with a focus on the kinetics of lactic acid pools. PLoS ONE 2013, 8, e68470. [CrossRef] [PubMed]

50. Karovičová, J.; Kohajdová, Z. Lactic acid fermented vegetable juices. Hortic. Sci. 2003, 30, 152-158. [CrossRef]

51. De, V.W.; Stouthamer, A.H. Pathway of glucose fermentation in relation to the taxonomy of bifidobacteria. J. Bacteriol. 1967, 93, 574-576.

52. Zhai, Z.Y.; Douillard, F.P.; An, H.; Wang, G.H.; Guo, X.H.; Luo, Y.B.; Hao, Y. Proteomic characterization of the acid tolerance response in Lactobacillus delbrueckii subsp. Bulgaricus CAUH1 and functional identification of a novel acid stress-related transcriptional regulator Ldb0677. Environ. Microbiol. 2014, 16, 1524-1537. [CrossRef] [PubMed]

53. Mousavi, Z.E.; Mousavi, S.M.; Razavi, S.H.; Emam-Djomeh, Z.; Kiani, H. Fermentation of pomegranate juice by probiotic lactic acid bacteria. World J. Microbiol. Biotechnol. 2011, 27, 123-128. [CrossRef]

54. Jelovac, N.; Perković, A.; Pupovac, M.; Trontel, A.; Slavica, A. Catabolism of amino acids in the cells of lactic acid bacteria. Biotechnol. Nutr. 2011, 6, 25-26.

55. Hebert, E.M.; Raya, R.R.; de Giori, G.S. Nutritional requirements of Lactobacillus delbrueckii subsp. lactis in a chemically defined medium. Curr. Microbiol. 2004, 49, 341-345. [CrossRef] [PubMed]

56. Van de Guchte, M.; Serror, P.; Chervaux, C.; Smokvina, T.; Ehrlich, S.D.; Maguin, E. Stress responses in lactic acid bacteria. Antonie Leeuwenhoek 2002, 82, 187-216. [CrossRef] [PubMed]

57. Garcia-Ruiz, A.; Gonzalez-Rompinelli, E.M.; Bartolome, B.; Moreno-Arribas, M.V. Potential of wine-associated lactic acid bacteria to degrade biogenic amines. Int. J. Food Microbiol. 2001, 148, 115-120. [CrossRef] [PubMed]

58. Lu, S.; Li, K. Biogenic amines in dry fermented sausages and the factors influencing their accumulation. Acta Agric. Boreal.-Occident. Sin. 2005, 14, 148-153.

59. Ávila, M.; Hidalgo, M.; Sánchez-Moreno, C.; Pelaez, C.; Requena, T.; Pascual-Teresa, S.d. Bioconversion of anthocyanin glycosides by Bifidobacteria and Lactobacillus. Food Res. Int. 2009, 42, 1453-1461. [CrossRef]

60. Filannino, P.; Bai, Y.; Di Cagno, R.; Gobbetti, M.; Gänzle, M.G. Metabolism of phenolic compounds by Lactobacillus spp. during fermentation of cherry juice and broccoli puree. Food Microbiol. 2015, 46, 272-279. [CrossRef]

61. Hunaefi, D.; Gruda, N.; Riedel, H.; Akumo, D.N.; Saw, N.M.M.T.; Smetanska, I. Improvement of antioxidant activities in red cabbage sprouts by lactic acid bacterial fermentation. Food Biotechnol. 2013, 27, $279-302$. [CrossRef]

62. Suthanthangjai, W.; Kilmartin, P.A.; Phillips, A.R.J.; Davies, K.; Ansell, J. Bioconversion of pinot noir anthocyanins into bioactive phenolic compounds by lactic acid bacteria. Nutr. Aging 2014, 2, 145-149. 
63. Liang, N.N.; Han, S.; Fei, H.E.; Liu, Y.; Wang, P.Y.; Wang, J.H. Correlation analysis of anthocyanin compositions and CIELab parameters during the process of wine fermentation by several red grape varieties. China Brew. 2014, 31, 48-55.

64. Schanda, J. CIE Colorimetry; Wiley-Blackwell: Hoboken, NJ, USA, 2007.

65. Di Cagno, R.; Minervini, G.; Rizzello, C.G.; De Angelis, M.; Gobbetti, M. Effect of lactic acid fermentation on antioxidant, texture, color and sensory properties of red and green smoothies. Food Microbiol. 2011, 28, 1062-1071. [CrossRef] [PubMed]

(C) 2019 by the authors. Licensee MDPI, Basel, Switzerland. This article is an open access article distributed under the terms and conditions of the Creative Commons Attribution (CC BY) license (http://creativecommons.org/licenses/by/4.0/). 